\title{
LYSIS AND PROTECTION OF ERYTHROCYTES BY T-MYCOPLASMAS
}

\author{
R. J. Manchee* and D. TAYLOR-Robinson $\dagger$ \\ Clinical Research Centre, Harvard Hospital, Salisbury, Wiltshire

\section{Plates LIII and LIV}

THE small size of T-mycoplasma colonies (Shepard, 1956) has been a drawback to the study of some of their properties. The incorporation of N-2-hydroxyethylpiperazine-N'-2-ethane-sulphonic acid (HEPES) buffer (Good et al., 1966) in the agar medium improves the size and morphology of the colonies and this has enabled such biological properties as colony haemadsorption and HeLa cell adsorption to be demonstrated (Manchee and Taylor-Robinson, 1969).

Shepard (1967) reported that colonies of T-mycoplasmas isolated from man produced a soluble haemolysin, which caused $\beta$-haemolysis of guinea-pig erythrocytes suspended in an agar overlay; the haemolytic zones varied from 0.5 to $2.0 \mathrm{~mm}$ in diameter. On the other hand, Sobeslavsky and Chanock (1968) failed to detect haemolysis of guinea-pig erythrocytes by colonies of three $\mathrm{T}$-mycoplasmas of human origin, but they suggested that this may have been due to the small size of the colonies.

The large colonies of T-mycoplasmas that we have obtained recently have enabled us to investigate with more certainty the haemolytic properties of strains isolated from man and from various animal species. In addition, during the course of this work we sometimes observed the prevention of erythrocyte lysis in the neighbourhood of T-mycoplasma colonies, a phenomenon also seen with the large-colony-forming mycoplasma Mycoplasma pneumoniae.

\section{MATERIALS AND METHODS}

Mycoplasmas. The mycoplasmas investigated and their origins are shown in table I.

Media. For the production of colonies, all mycoplasma strains were grown on agar medium containing HEPES buffer (Sigma Chemical Company Ltd, London, S.W.6) as described previously (Manchee and Taylor-Robinson). The $p \mathrm{H}$ of the medium was, however, adjusted to 6.5 with $\mathrm{N}-\mathrm{HCl}$ rather than to $\mathrm{pH} 6.8$ as in the earlier studies.

Benzidine blood agar (BBA) medium for the detection of peroxide was similar to that used by Cole, Ward and Martin (1968). It consisted of the HEPES-agar medium described above supplemented with 4 per cent. guinea-pig erythrocytes and 0.01 per cent. benzidine. Liquid medium without the buffer was used to dilute stock suspensions of the mycoplasmas.

Erythrocytes. Guinea-pig, squirrel monkey, dog, bull and human blood were collected into heparin. The erythrocytes were washed three times in either Difco PPLO broth or Alsever's solution and used on the day of collection.

Production of colonies. $0.1 \mathrm{ml}$ of mycoplasma stock culture diluted to contain between

Received 3 Dec. 1969; accepted 8 Jan. 1970.

* Present addresses: Microbiological Research Establishment, Porton, near Salisbury, Wilts., and † Clinical Research Centre, Watford Road, Harrow, Middlesex, HA1 3UJ. (Reprints from D.T.-R.)

J. MED. MICROBIOL.-VOL. 3 (1970) 
$10^{2}$ and $10^{3}$ colony-forming units (CFU) per $\mathrm{ml}$ was inoculated on HEPES-agar medium in 5-cm plastic petri dishes (Esco Rubber Ltd, London). Cultures were incubated at $37^{\circ} \mathrm{C}$ in a moist atmosphere of 95 per cent. $\mathrm{N}_{2}$ and 5 per cent. $\mathrm{CO}_{2}$. After 2-3 days' incubation ( 5 days for $M$. pneumoniae), the position of the colonies was marked on the base of the petri dish with a grease-pencil.

Test for haemolysis. The standard conditions for the demonstration of haemolysis by T-mycoplasmas were (i) growth on HEPES-agar medium at $p \mathrm{H} 6 \cdot 5$, (ii) incubation of cultures for 2-3 days under anaerobic conditions, (iii) overlaying the colonies with $2.5 \mathrm{ml}$ of a 3 per cent. suspension of guinea-pig erythrocytes in HEPES-agar medium at $p \mathrm{H} 6.5$ (Somerson, Taylor-Robinson and Chanock, 1963), and (iv) re-incubation at $37^{\circ} \mathrm{C}$ in air. All cultures were examined by naked eye and microscopically $(\times 100)$ for haemolysis at intervals of $24 \mathrm{hr}$ or less.

Detection of peroxide. Two direct methods were used. (a) Mycoplasmas were grown in liquid medium and concentrated 100 -fold by centrifugation, and the deposited organisms were inoculated on the surface of BBA medium. The cultures were incubated aerobically at $37^{\circ} \mathrm{C}$ for 10 days. Peroxide production was indicated by the development of dark coloration of the mycoplasma growth. (b) $0 \cdot 1 \mathrm{ml}$ of mycoplasma stock culture diluted to contain between $10^{2}$ and $10^{3} \mathrm{CFU}$ per $\mathrm{ml}$ was inoculated on BBA medium and incubated at $37^{\circ} \mathrm{C}$ in an atmosphere of 95 per cent. $\mathrm{N}_{2}$ and 5 per cent. $\mathrm{CO}_{2}$ until colonies were visible. The cultures were then incubated aerobically for 15 days. Peroxide production was indicated by the development of dark-brown spots within the areas of colony growth.

An indirect method, namely the inhibitory effect of catalase on the production of zones of haemolysis, was also used. Catalase (Boehringer Corporation Ltd, London, W.5) was incorporated in the erythrocyte-agar overlay at a final concentration of 10,000 units per $\mathrm{ml}$. In some experiments the activity of the catalase was specifically inhibited with 3-amino-1,2,4triazole (AT; Koch-Light Ltd, Colnbrook, Bucks.) which was incorporated in the overlay at a final concentration of 0.35 per cent.

\section{RESULTS \\ Lysis of erythrocytes}

Under the standard conditions described above, colonies of each of the mycoplasma strains shown in table I, with the exception of strain 960, were tested with homologous erythrocytes. In other words, the simian T-mycoplasma was tested with squirrel monkey erythrocytes, the mycoplasmas isolated from man with human erythrocytes, etc. Zones of haemolysis with diffuse edges, containing a moderate number of unaltered corpuscles, and without green coloration, occurred. This was similar to the $\alpha^{\prime}$ (alpha-prime) type of haemolysis described for streptococci (Wilson and Miles, 1964). In addition, all the mycoplasma strains were tested with guinea-pig erythrocytes; the degree of haemolysis was comparable with that obtained with the homologous erythrocytes, except in the case of $M$. pneumoniae colonies, which now produced typical $\beta$-haemolytic zones. In further studies of lysis only guinea-pig erythrocytes were used. Haemolysis with T-mycoplasmas was rarely seen on plates with more than 100 colonies; in the subsequent tests, therefore, an inoculum was used that gave less than this number. Colonies of $M$. pneumoniae were examined in each test because of their known ability to lyse erythrocytes and, as seen from table II, this was the only mycoplasma that consistently lysed the guinea-pig erythrocytes. The various T-mycoplasmas caused haemolysis in only a proportion of the tests, one of the human strains (REOW) not causing haemolysis in any instance. 
Haemolysis by $M$. pneumoniae was first detectable $12 \mathrm{hr}$ after overlaying, but in the case of the T-mycoplasmas it was rarely detectable before $48 \mathrm{hr}$ and usually not until after $72 \mathrm{hr}$. Haemolysis by T-mycoplasma colonies was

TABLE I

Mycoplasmas investigated

\begin{tabular}{|c|c|}
\hline Designation & Origin \\
\hline $\begin{array}{l}\text { T-colony-forming } \\
\text { Simian (SP1625) } \\
\text { Canine (SP1701) } \\
\text { Bovine (SP1637) } \\
\text { Human } \\
\text { Johnson } \\
\text { REOW* } \\
960 \dagger \\
\text { SP1106 }\end{array}$ & $\begin{array}{l}\text { Throat of squirrel monkey } \\
\text { Semen of Welsh terrier } \\
\text { Preputial cavity of Guernsey bull } \\
\text { Throat of male adult } \\
\text { Urogenital tract } \\
\text { Urogenital tract } \\
\text { Urethra of male adult }\end{array}$ \\
\hline $\begin{array}{l}\text { Large-colony-forming } \\
\text { M. pneumoniae }(\mathrm{FH}) \dagger\end{array}$ & Respiratory tract \\
\hline
\end{tabular}

* Supplied by Professor R. E. O. Williams.

† Supplied by Dr R. M. Chanock.

TABLE II

Haemolysis of homologous and guinea-pig erythrocytes

\begin{tabular}{|c|c|c|c|c|}
\hline \multirow{3}{*}{$\begin{array}{c}\text { Strain of } \\
\text { mycoplasma }\end{array}$} & \multicolumn{4}{|c|}{ Haemolysis of } \\
\hline & \multicolumn{2}{|c|}{ homologous RBC } & \multicolumn{2}{|c|}{ guinea-pig RBC } \\
\hline & $\begin{array}{c}\text { Number of } \\
\text { tests }\end{array}$ & $\begin{array}{l}\text { Number } \\
\text { positive }\end{array}$ & $\underset{\text { tests }}{\text { Number of }}$ & $\begin{array}{l}\text { Number } \\
\text { positive }\end{array}$ \\
\hline \multicolumn{5}{|l|}{$\mathrm{T}$-mycoplasmas } \\
\hline Simian & 1 & 1 & 17 & 7 \\
\hline Canine & 2 & 1 & 18 & 15 \\
\hline Bovine & 1 & 1 & 15 & 4 \\
\hline Human & & 0 & & \\
\hline $\begin{array}{l}\text { Jonnson } \\
\text { REOW }\end{array}$ & $\begin{array}{l}1 \\
1\end{array}$ & 0 & $\begin{array}{r}0 \\
11\end{array}$ & 0 \\
\hline 960 & $\cdots$ & $\cdots$ & 4 & 1 \\
\hline $\begin{array}{l}\text { SP1106 } \\
\text { nnempige }\end{array}$ & 1 & 0 & 11 & 3 \\
\hline M. pneumoniae & 1 & 1 & 12 & 12 \\
\hline
\end{tabular}

infrequently seen with the naked eye. Their haemolytic zones were usually about $150 \mu \mathrm{m}$ in diameter, zones of $2 \mathrm{~mm}$ being exceptional. Most often the slight degree of haemolysis was detectable only with the low power of the microscope. The haemolysis was usually of the $\alpha^{\prime}$-type, sometimes becoming $\beta$-type on prolonged incubation at a time when general autolysis of the erythrocytes in the overlay was occurring (figs. 1 and 2). 
Variations from standard conditions. The effect of the age of colonies was studied with three T-mycoplasmas (simian, canine, and human SP1106) and $M$. pneumoniae. Colonies that had grown for 24,48 and $72 \mathrm{hr}$ were overlaid and examined for haemolytic activity. The size of the zones of haemolysis did not vary with the age of the colonies. The use of agar medium at $p \mathbf{H ~} 6.0$ for growth of colonies before overlaying did not lead to larger zones of haemolysis. Varying the $p \mathrm{H}$ of the overlay over a range from 6.0 to 8.0 did not significantly change the size of the zones. The addition of 1.0 per cent. glucose to the overlay did not increase haemolytic activity, although Cohen and Somerson (1969) found that addition of glucose stimulated the production of hydrogen peroxide by $M$. pneumoniae and $M$. gallisepticum. At various times after overlay cultures were transferred from $37^{\circ} \mathrm{C}$ to $4^{\circ} \mathrm{C}$ for periods of up to $72 \mathrm{hr}$, but this neither enhanced haemolysis present at the time of transfer nor caused it to occur if it was absent. Haemolysis failed to occur if cultures, after overlaying, were re-incubated anaerobically, i.e., in 95 per cent. $\mathrm{N}_{2}$ and 5 per cent. $\mathrm{CO}_{2}$.

\section{Detection of peroxide production}

Direct methods. Since it has been shown that a peroxide is the major haemolysin of the Mycoplasma group (Cole, Ward and Martin), attempts were made to detect its production by the T-mycoplasmas shown in table I. Centrifuge deposits of T-mycoplasma organisms on BBA medium did not develop dark coloration after 10 days' incubation, whereas a deposit of similarly concentrated $M$. pneumoniae organisms did so after 3 days' incubation. In addition, T-mycoplasma colonies on BBA medium did not develop darkbrown spots after incubation for 15 days, but $M$. pneumoniae colonies did after 5 days (fig. 3).

Indirect method. If haemolysis by T-mycoplasmas is due to peroxide it seems likely that very little of this is produced, and the failure to detect it by direct methods might be due to their lack of sensitivity. An indirect approach was used therefore, namely, the incorporation of catalase in the erythrocyteagar overlay. The canine T-mycoplasma was used for this experiment since it was the only one with which we were able to demonstrate haemolysis consistently. The presence of the catalase resulted in inhibition of the haemolytic activity of both $M$. pneumoniae and the canine T-mycoplasma, suggesting that the haemolysin produced by the latter is also a peroxide.

Incorporation of 0.35 per cent. AT in the overlay together with the catalase inhibited the activity of the latter and zones of haemolysis were produced. In the case of $M$. pneumoniae the zones were the same size as those produced in the absence of catalase, but in the case of the canine T-mycoplasma they were slightly larger.

\section{Protection of erythrocytes from haemolysis}

Prolonged incubation of overlaid cultures led to autolysis of erythrocytes in the overlay. However, in initial experiments with $\mathrm{T}$-mycoplasmas and homologous erythrocytes it was observed that at the time of general autolysis some 
erythrocytes were preserved around the colonies that had developed haemolytic zones earlier. In subsequent tests with guinea-pig erythrocytes this phenomenon of erythrocyte preservation (fig. 4) was observed with all the T-mycoplasmas investigated and with some of them it occurred more frequently than haemolysis (table III). It was not confined to the T-mycoplasmas since it was observed also with $M$. pneumoniae; with this organism dog and bovine erythrocytes were preserved much better than guinea-pig erythrocytes (figs. 5 and 6). As with haemolysis, preservation of erythrocytes around colonies of T-mycoplasmas

TABLE III

Protection from haemolysis of homologous and guinea-pig erythrocytes

\begin{tabular}{|c|c|c|c|c|}
\hline \multirow{3}{*}{$\begin{array}{c}\text { Strain of } \\
\text { mycoplasma }\end{array}$} & \multicolumn{4}{|c|}{ Protection of } \\
\hline & \multicolumn{2}{|c|}{ homologous RBC } & \multicolumn{2}{|c|}{ guinea-pig RBC } \\
\hline & $\begin{array}{c}\text { Number of } \\
\text { tests }\end{array}$ & $\begin{array}{l}\text { Number } \\
\text { protected }\end{array}$ & $\underset{\text { tests }}{\text { Number of }}$ & $\begin{array}{l}\text { Number } \\
\text { protected }\end{array}$ \\
\hline $\begin{array}{l}\text { T-mycoplasmas } \\
\text { Simian } \\
\text { Canine } \\
\text { Bovine } \\
\text { Human } \\
\text { Johnson } \\
\text { REOW } \\
960 \\
\text { SP1106 } \\
\text { M. pneumoniae }\end{array}$ & $\begin{array}{r}1 \\
2 \\
1 \\
1 \\
1 \\
\cdots \\
1 \\
1\end{array}$ & $\begin{array}{r}0 \\
1 \\
0 \\
1 \\
1 \\
\cdots \\
1 \\
1\end{array}$ & $\begin{array}{r}17 \\
18 \\
15 \\
\\
6 \\
11 \\
4 \\
11 \\
12\end{array}$ & $\begin{array}{r}6 \\
11 \\
3 \\
3 \\
3 \\
2 \\
5 \\
7^{*}\end{array}$ \\
\hline
\end{tabular}

and $M$. pneumoniae did not occur if large numbers of colonies (i.e., $>100$ ) were present. The phenomenon was not inhibited by the incorporation in the overlay of either catalase or 0.35 per cent. AT.

\section{Discussion}

We have observed that $\mathrm{T}$-mycoplasmas isolated from man and several animal species are capable of causing lysis of homologous erythrocytes and those of guinea-pigs. Haemolysis was usually of the $\alpha^{\prime}$-type, and was often detectable only by examination with the low power of the microscope. In contrast, that caused by colonies of $M$. pneumoniae was easily seen with the naked eye, and with guinea-pig erythrocytes was clearly $\beta$-haemolysis. Furthermore, haemolysis by $\mathrm{T}$-mycoplasmas, in comparison with that caused by $M$. pneumoniae, was not consistently demonstrable from one test to another, nor even in duplicate cultures within the same test. Failure to demonstrate haemolysis could not be attributed to poor colony development. For example, colonies of the bovine $\mathrm{T}$-mycoplasma, with which haemolysis was not easily demonstrated, were sometimes $350 \mu \mathrm{m}$ in diameter. It seems, therefore, that 
the inability to demonstrate haemolysis consistently is due to haemolysin being produced in small quantity. We were unable to improve haemolysin production by making various alterations in the cultural conditions. On the other hand, Fabricant and Freundt (1967) showed that minor variations in the composition of medium produced significant variations in the results of some commonly used laboratory tests for mycoplasmas, and they commented upon the need for standardisation of conditions. However, we feel that even if haemolysis by $\mathrm{T}$-mycoplasmas could be achieved with greater regularity it is so weak as to be useless as a practical aid to identification.

The production of a soluble haemolysin by $M$. pneumoniae was demonstrated by Clyde (1963) and by Somerson et al. (1963). Somerson, Walls and Chanock (1965) identified the haemolysin as hydrogen peroxide. Subsequently, Cole et al. (1968) examined many different mycoplasma species and found that practically all of them lysed erythrocytes by the production of peroxide, although it is probable that other factors also played a part in the haemolysis caused by some of them. We were unable to detect peroxide formation by T-mycoplasmas by direct methods, but we were able to inhibit haemolysis by the canine T-mycoplasma with catalase. The effect of catalase was prevented by the additional incorporation of its specific inhibitor AT (Margoliash, Novogrodsky and Schejter, 1960). These results showed that peroxide was responsible for the haemolytic effect.

T-mycoplasmas have a number of characteristics in common with mycoplasmas in general (Taylor-Robinson et al., 1969) and the evidence that T-mycoplasmas also produce a peroxide haemolysin further supports the biological relationship. Whether peroxide formation by T-mycoplasmas has pathogenic significance is unknown. Sobeslavsky and Chanock (1968) have suggested that the relatively large amount of peroxide produced by $M$. pneumoniae is an important factor in its pathogenicity for man. The small amount of peroxide produced by $\mathrm{T}$-mycoplasmas might, therefore, be an indication of non-pathogenicity. However, peroxide production by mycoplasmas, if it is a factor in pathogenicity, cannot be the only one since the saprophytic $M$. laidlawii produces a peroxide haemolysin and Lipman and Clyde (1969) have shown that a non-pathogenic mutant of $M$. pneumoniae produces as much peroxide as a pathogenic strain.

The inhibition of autolysis of guinea-pig erythrocytes around colonies of M. pulmonis was seen by Fallon and Jackson (1967). A similar effect was noted with $M$. salivarium by Cole et al., but apparently they did not observe this pienomenon with any of the other mycoplasmas that they examined. Lipman and Clyde alluded to its occurrence with colonies of $M$. pneumoniae. Most workers studying haemolysis by $M$. pneumoniae have not commented on the protective phenomenon, possibly because they used guinea-pig erythrocytes which, as we have shown, are much less suitable for demonstrating the effect than bovine and dog erythrocytes. The protective effect, however, was a notable feature in our tests with T-mycoplasmas, being observed as often as haemolysis. Indeed, it is possible that its presence might at times obscure haemolysis if haemolysin is produced in small quantities, as appears to be the 


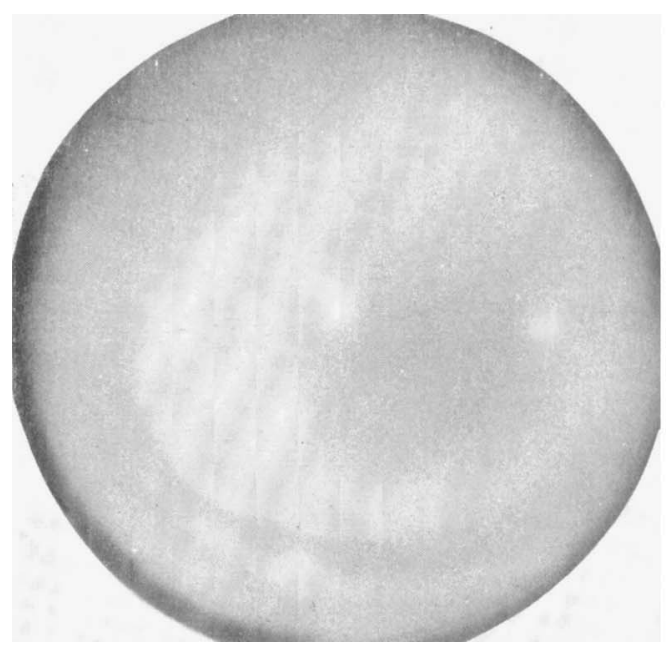

FIG. 1.- Two zones of haemolysis of squirrel monkey erythrocytes caused by simian T-mycoplasma colonies, after overlaying with erythrocyte-agar and aerobic incubation at $37^{\circ} \mathrm{C}$ for $96 \mathrm{hr}$. General autolysis of erythrocytes was also occurring at this time. $\times 1.5$.

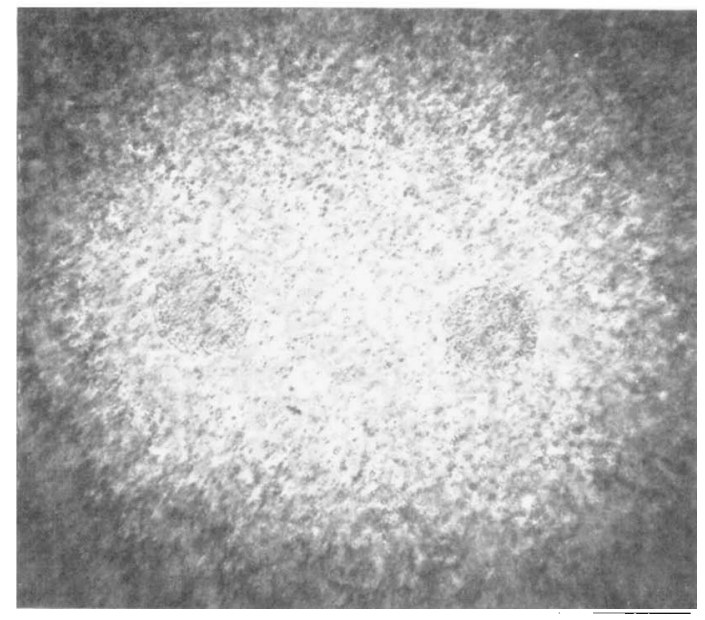

FIG. 2.-Haemolysis of guinea-pig erythrocytes by colonies of the bovine T-mycoplasma after overlaying and aerobic incubation at $37 \mathrm{C}$ for $96 \mathrm{hr}$. x. 40 .

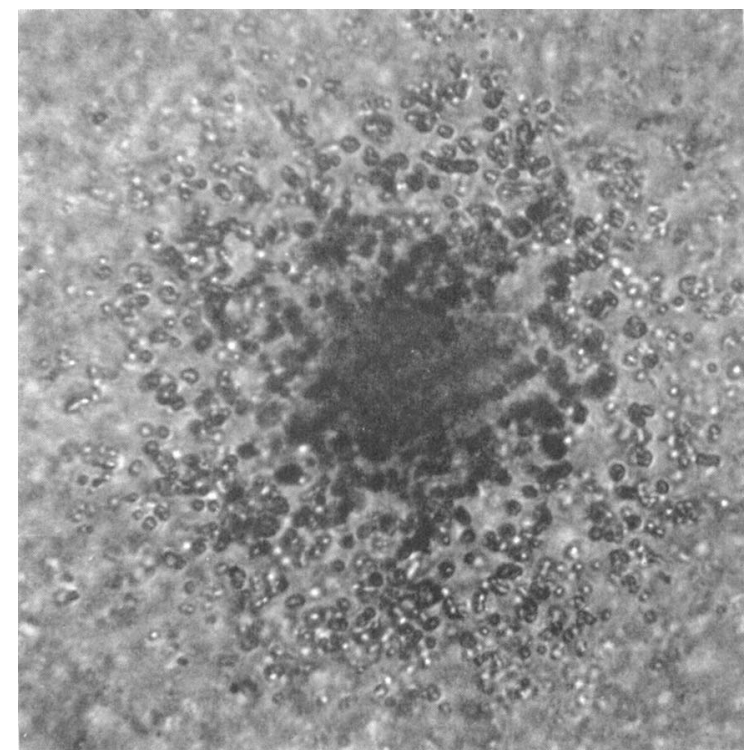

FIG. 3.-Dark spots in a colony of $M$. pneumoniae grown on benzidine blood agar medium. Photograph taken after 5 days of aerobic incubation at $37^{\circ} \mathrm{C} . \quad \times 120$. 


\section{LYSIS OF ERYTHROCYTES BY T-MYCOPLASMAS}



FIG. 4.-Areas of preserved guinea-pig erythrocytes around colonies of the human T-mycoplasma SP1106. Photograph taken after overlaying and aerobic incubation at $37 \mathrm{C}$ for $96 \mathrm{hr}$ when general autolysis of erythrocytes had occurred. $\times 1.5$.

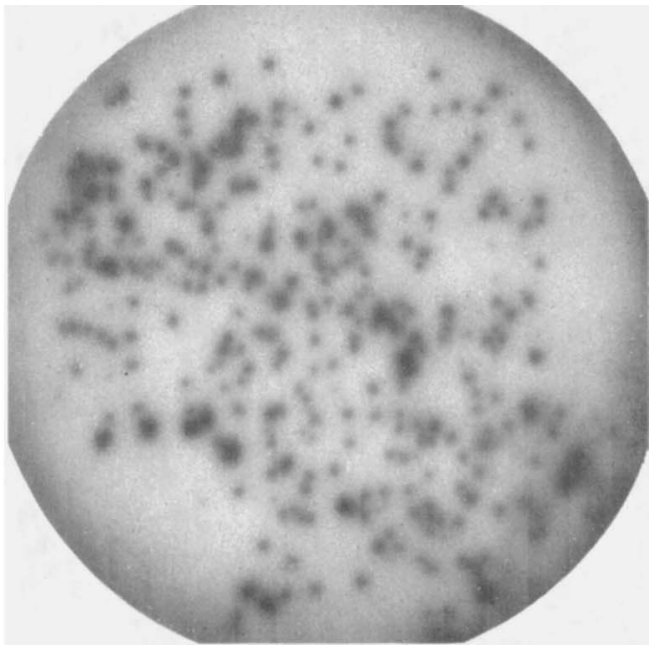

FiG. 5.-Areas of preserved canine erythrocytes around colonies of $M$. pneumoniae. Photograph taken as in fig. $4 . \times 1.5$.

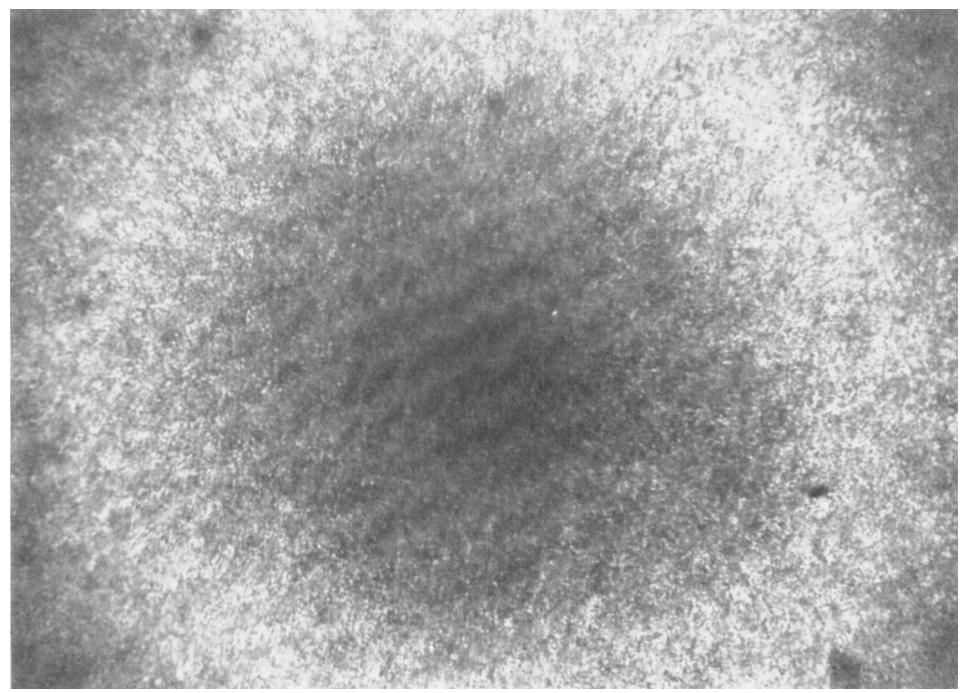

FiG. 6.-An inner zone of preserved bovine erythrocytes and an outer zone of lysed erythrocytes around a colony of $M$. pneumoniae. Photograph taken as in fig. 4 . General autolysis of erythrocytes has not yet begun. $\times 75$. 
case with T-mycoplasmas. The nature of the protective factor is unknown, but it would seem to be fairly potent since it is effective in the area of maximal haemolysin activity. It does not appear to be due to a specific local $p \mathrm{H}$ effect, as $M$. pneumoniae produces acid and T-mycoplasmas produce alkali. Catalase production by some mycoplasmas has been reported by several workers (cited by Cole et al.). It does not seem likely, however, that catalase is responsible for the protection of erythrocytes, because the latter effect still occurs in the presence of the catalase inhibitor amino-triazole. On the other hand, Cohen and Somerson (1969) have reported peroxidase-like activity by $M$. pneumoniae and it is possible that such a peroxidase, not susceptible to amino-triazole, is responsible for the protective effect.

\section{SUMMARY}

Colonies of T-mycoplasmas isolated from a monkey, a dog, a bull and man lysed erythrocytes suspended in an agar overlay. Haemolysis was of the $\alpha^{\prime}$ (alpha-prime) type, and was usually detectable only with the low power of the microscope. As compared with $M$. pneumoniae, T-mycoplasma haemolysis occurred inconsistently in repeated tests. Crowding of colonies inhibited haemolysis. The addition of catalase also inhibited haemolysis indicating that the T-mycoplasma haemolysin is a peroxide. This haemolysin is probably produced in only small amounts. Protection of erythrocytes against lysis in the close proximity of the colonies of T-mycoplasmas and $M$. pneumoniae was also observed. This phenomenon occurred as frequently as haemolysis, and may have contributed to the difficulty experienced in detecting weak haemolysis. It too was inhibited by crowding of colonies. The protective effect was not due to catalase production, and it is suggested that a peroxidase might be responsible.

We thank Mr G. C. Bantin, Animal Services Section, B.D.H. Ltd, Godalming, Surrey, for supplying blood from squirrel monkeys, Mr R. R. Henry of the Salisbury Poultry Laboratories for blood from dogs and Mr P. L. Dawson of the Hampshire Cattle Breeders Society A.I. Centre, Lyndhurst, for blood from bulls.

\section{REFERENCES}

ClYde, W. A., JR $\quad$. $\quad$. $\quad$. $\quad$. 1963. Science, N.Y., 139, 55.

COHEN, G., AND Somerson, N. L. . . 1969. J. Bact., 98, 547.

COle, B. C., WARD, J. R., AND MARTIN, 1968. Ibid., 95, 2022. C. $\mathrm{H}$.

FABRICANT, J., AND FreUndt, E. A.

FALLON, R. J., AND JACKSON, D. K.

1967. Ann. N.Y. Acad. Sci., 143, 50.

1967. Lab. Anim., 1, 55.

GOOD, N. E., WINGET, G. D., WINTER, W., 1966. Biochemistry, 5, 467.

ConNolly, T. N., IzaWa, S., AND

SINGH, R. M. M.

Lipman, R. P., and Clyde, W. A., JR . 1969. Proc. Soc. Exp. Biol. Med., 131, 1163.

MANCHEE, R. J., AND TAYLOR-Robinson, 1969. J. Bact., $100,78$. D.

Margoliash, E., Novogrodsky, A., 1960. Biochem. J., 74, 339. AND SCHEJTER, A. 
SHEPARD, M. C. . $\quad$ - $\quad$ - $\quad$. 1956. J. Bact., 71, 362.

, $\quad . \quad$. * . 1967. Ann. N.Y. Acad. Sci., 143, 505.

Sobeslavsky, O., and Chanock, R. M. 1968. Proc. Soc. Exp. Biol. Med., 129, 531.

Somerson, N. L., TAylor-Robinson, D., 1963. Amer. J. Hyg., 77, 122.

AND Chanock, R. M.

Somerson, N. L., Walls, B. E., AND 1965. Science, N.Y., 150, 226. CHANOCK, R. M.

TAylor-Robinson, D., Addey, Jean P., 1969. Br. J. Vener. Dis., 45, 265.

Hare, M. J., AND Dunlop, E. M. C.

Wilson, G. S., AND Miles, A. A. . . 1964. In Topley and Wilson's Principles of bacteriology and immunity, 5th ed., London, vol. 1, p. 697. 